\title{
ЗАРУБЕННЫЙ ОПЫТ
}

\section{А. Ф. Расулев, А. В. Тростянский}

УДК 338.23(575.1)

\section{СОВРЕМЕННЫЕ АСПЕКТЫ ОБЕСПЕЧЕНИЯ ЭКОНОМИЧЕСКОЙ БЕЗОПАСНОСТИ УЗБЕКИСТАНА}

В статье раскрывается динамика основных индикаторов обеспечения экономической безопасности Узбекистана на современном этапе развития.

Особое внимание уделяется макро- и мезоэкономическим аспектам устойчивого развития национальной экономики, реализации институциональных реформ по обеспечению конкуренции, а также благоприятного инвестищионного и предпринимательского климата. Раскрываются потенциальные риски и угрозы экономики республики в области движения капитала, сокращения экспортных доходов, напряженности на рынке труда, а также основные направления повышения конкурентоспособности на территориальном и отраслевом уровне. Авторы предлагают оценить конкурентный потенциал секторов начиональной экономики с учетом территориально-отраслевых особенностей. В статье рассматриваются главные составляющие внутренней экономической политики, которые взаимно дополняют и усиливают друг друга и от правильной комбинации которых зависит успех в реализации стратегии роста конкурентоспособности.

Ключевые слова: экономическая безопасность, потенциальные риски и угрозы, пороговые значения, стратегия роста конкурентоспособности

В настоящее время для оценки экономической безопасности установлен целый ряд индикаторов, отражающих практически все стороны развития национальной экономики и позволяющих выявить как внешние, так и внутренние потенциальные риски, а также предупредить их негативные последствия. Особого внимания заслуживают величины их пороговых значений, представляющие собой количественные показатели предельно допустимых величин с позиции соблюдения национальных интересов. Исходя из мировой практики, в системе экономической безопасности Узбекистана они условно могут быть сгруппированы следующим образом:

- макроэкономические показатели, отражающие устойчивость национальной экономики к внешним риска и угрозам;

- мезоэкономические показатели, отражающие уязвимость отдельных областей и отраслей к потенциальным внешним и внутренним рискам и угрозам.

- микроэкономические показатели, отражающие внешние и внутренние угрозы и риски.
В целом по основным индикаторам экономической безопасности экономика республики характеризуется позитивными тенденциями (табл. 1). Так, темпы роста ВВП в 2011 г. составили 8,3\%, а за период 2000-2011 гг. объем ВВП увеличился в 2,1 раза. Конкретным подтверждением устойчивого и сбалансированного развития экономики Узбекистана является то, что начиная с 2005 г. государственный бюджет исполняется с профицитом. Расходная часть государственного бюджета выросла по сравнению с 2000 г. в 17,8 раза. 58,7\% расходов госбюджета направлены на финансирование социальной сферы и поддержку населения. По состоянию на 1 января 2012 г. величина совокупной внешней задолженности Узбекистана не превышает 17,5\% от ВВП и 53,7\% к объему экспорта, что по международным критериям экономической безопасности ниже пороговых значений. Это обусловлено проводимой в республике политике внешнего заимствования, как на уровне государства, так и на уровне коммерческих банков, компаний и предприятий. 
Динамика показателей экономической безопасности экономики Узбекистана

\begin{tabular}{|c|c|c|}
\hline Показатели экономической безопасности & 2000 г. & 2011 г. \\
\hline Темпы роста ВВП & 3,8 & 8,3 \\
\hline ВВП на душу населения по ППС, долл. США & 1431 & 3271 \\
\hline Дефицит бюджета & $-4,2$ & $+0,3$ \\
\hline Налоговое бремя, \% к ВВП & 39,5 & 22 \\
\hline Инфляция, \% & н/д & 7,3 \\
\hline Внешний долг, \% к ВВП & н/д & 17,5 \\
\hline Внешний долг, \% к экспорту & н/д & 53,7 \\
\hline Структура кредитного портфеля банков & $\begin{array}{l}\text { 54\% - внешние } \\
\text { заимствования }\end{array}$ & $\begin{array}{l}\text { 85\% - депозиты юриди- } \\
\text { ческих и физических лиц }\end{array}$ \\
\hline Объемы инвестиций, \% к ВВП & 22,9 & 23,5 \\
\hline Процент покрытия импорта экспортом, \% & 110,7 & 143,0 \\
\hline Удельный вес готовой продукции в объеме экспорта & 46 & 60 \\
\hline Доля индустриального комплекса в ВВП & 14,2 & 24,1 \\
\hline Доля в промышленном производстве машиностроения & 9,8 & 16,1 \\
\hline Доля услуг в ВВП & 37 & 49 \\
\hline Коэффициент Джини & 0,39 & 0,30 \\
\hline Расходы на образование в структуре расходов госбюджета & 23,2 & 33,3 \\
\hline
\end{tabular}

Устойчивыми темпами роста характеризуются промышленное производство - 6,3\%, производство продукции сельского хозяйства - $6,6 \%$, объем розничного товарооборота $16,4 \%$ и реализация платных услуг населению - $16,1 \%$. Около $70 \%$ прироста объема промышленного производства обеспечили предприятия, ориентированные на выпуск продукции с высокой добавленной стоимостью. Если в 2000 г. на долю индустриального производства в формировании валового внутреннего продукта Узбекистана приходилось всего $14,2 \%$, то в 2011 г. она составила $24,1 \%$.

Структурные сдвиги и диверсификация базовых отраслей экономики оказали позитивное влияние на объем, номенклатуру и качество экспорта. Объем экспортной продукции в 2011 г. увеличился по сравнению с 2000 г. в 4,6 раза и превысил 15 млрд долл. США, положительное сальдо внешнеторгового оборота достигло более 4,5 млрд долл. США. Удельный вес готовой продукции в объеме экспорта увеличился до $60 \%$ против 46\% в 2000 г. При этом необходимо отметить, что объем производства потребительских товаров вырос за данный период более чем в 4 раза.

В республике осуществлляются масштабные институциональные преобразования в рамках реализации Концепции дальнейшего углубления демократических реформ. Направленность их структурируется как:
- реформирование институтов государства в системе экономического регулирования;

- приватизация государственной собственности;

- развитие рыночной инфраструктуры;

- создание благоприятной среды становления и развития малого бизнеса и частного предпринимательства;

- развитие конкуренции и ограничение монополизма.

Процесс формирования правового поля в Узбекистане носит динамичных характер, направленный на максимальное сокращение субъективных факторов, препятствующих становлению класса реальных собственников. Совершенствование законодательно-нормативной базы осуществляется в двух направлениях, а именно:

- создание единого унифицированного нормативно-правового акта, отражающего основные потребности предпринимательства и устанавливающего общие правила поведения для его субъектов;

- систематизация действующих правовых норм с дополнением недостающих элементов системы регулирования.

Важнейшей составляющей частью масштабных экономических реформ является формирование максимальной деловой среды для дальнейшего развития предпринимательства. Одним из главных направлений в данной области явля- 
ется дальнейшее сокращение надзорных и управленческих функций органов государственной власти и управления, упрощение административных действий, пресечение незаконного вмешательства в деятельность хозяйствующих субъектов. В целях устранения излишних бюрократических барьеров и создания благоприятных условий на пути развития частной собственности с 1 сентября 2011 г. было отменено действие 50 документов разрешительного характера, ограничивающих свободу предпринимательской деятельности. Кроме того, было запрещено введение органами государственного управления и органами государственной власти на местах новых видов разрешений и разрешительных процедур, не предусмотренных законодательством. Дальнейшей либерализации экономики послужило упрощение процедур и сокращение затрат субъектов предпринимательства при получении лицензии.

Институционально государственная политика в области реформ обеспечивает необходимую правовую среду и институты, ответственные за осуществление конкурентной политики на соответствующем уровне. При этом мы исходим из того принципа, что рыночные механизмы будут работать только тогда, когда рынок не будет чрезмерно зарегулирован. В противном случае есть опасность того, что конкуренция будет заменена государственным регулированием, ограничивающем свободу деятельности предприятий. Такая политика может во-первых, привести к подавлению настоящей рыночной конкуренции, а во-вторых, ослабить потенциально сильных национальных производителей в их конкурентной борьбе на внешних рынках. Что противоречит основным принципам «узбекской модели», признанной мировым сообществом.

Развитие конкуренции предполагает рост числа рыночных игроков, которые расширяют сегменты рынка и формируют новые элементы конкурентной среды. Важнейшим из них в условиях переходной экономики явилась приватизация государственной собственности. Данный процесс в Узбекистане носит многоэтапный характер, каждый из этапов основывается на соответствующих механизмах и правовой базе. На первых этапах приватизационного процесса преобладающим являлся частичный выкуп на основе «поточного» метод с использованием индсайдеровской модели корпоративного управления и создания правовой базы для функцио- нирования принципиально новых институтов регулирования. Он заключался в преобразованиях управляющих структур - министерств новых акционерных обществ в ассоциации, холдинги и т. д., деятельности инфраструктуры для свободного перелива акционерного капитала. Последующие этапы в целом были направлены на качественные изменения в структуре собственности, связанные с дерегулированием микроуровневых процессов. Изменяется и сама модель приватизации, от стандартных схем переходят к индивидуальным методам, учитывающим особенности финансового состояния, возможности реструктуризации и перепрофилирования.

На нынешнем этапе приватизации приоритетом остается широкое развитие частного предпринимательства, создание предприятий, основанных на частной собственности, в том числе в результате приватизации государственного имущества, и на этой основе значительное повышение доли частного сектора в структуре экономики (табл. 2).

Расширение масштабов воздействия процессов глобализации обуславливает необходимость создания дополнительных условий для дальнейшего повышения конкурентоспособности отечественных производителей на внутреннем и внешнем товарных рынках.

При совершенствовании антимонопольного законодательства в республике исходили из основного принципа конкурентной политики - перейти от жесткого регулирования деятельности предприятий-монополистов к предупреждению их неконкурентного поведения на рынке. При этом принималось во внимание, что доминирующее положение предприятия может свидетельствовать и об его эффективном функционировании и быть важной предпосылкой конкурентоспособности на внешнем рынке. Принятие нового Закона «О конкуренции» позволило консолидировать нормы, регулирующие отношения в сфере конкуренции, что повысило прозрачность и эффективность правового регулирования отношений в этой области, а также обеспечило равные условия для деятельности субъектов предпринимательства. Это является важнейшим аспектом развития конкуренции и ее защиты на рынках товаров и услуг республики.

В этой связи следует особо подчеркнуть важнейшие достижения биржевой торговли - запуск новых инструментов, а именно фьючерсных контрактов, ввод торгового терминала и ин- 
Таблица 2

Динамика формирования конкурентной среды на основе приватизации (по данным Госкомстата РУз)

\begin{tabular}{|c|c|c|c|}
\hline \multirow{2}{*}{ Годы } & \multirow{2}{*}{$\begin{array}{c}\text { Кол-во приватизированных } \\
\text { предприятий }\end{array}$} & \multicolumn{2}{|c|}{ в том числе } \\
\cline { 2 - 4 } & 9744 & 29,7 & 70,3 \\
\hline 1994 & 8537 & 12,0 & 88,0 \\
\hline 1995 & 915 & 65,6 & 34,4 \\
\hline 1996 & 899 & 50,7 & 49,3 \\
\hline 1997 & 266 & 41,4 & 58,6 \\
\hline 1998 & 373 & 37,8 & 62,2 \\
\hline 1999 & 372 & 40,8 & 59,2 \\
\hline 2000 & 1238 & 18,3 & 81,7 \\
\hline 2001 & 1800 & 12,4 & 87,6 \\
\hline 2002 & 1452 & 5,2 & 94,8 \\
\hline 2003 & 1228 & 2,3 & 97,7 \\
\hline 2004 & 980 & 0,3 & 99,7 \\
\hline 2005 & 673 & 2,8 & 97,2 \\
\hline 2006 & 631 & 0 & 100 \\
\hline 2007 & 392 & 0 & 100 \\
\hline 2008 & 135 & 0 & 100 \\
\hline 2009 & 96 & 0 & 100 \\
\hline 2010 & 30731 & 21,5 & 78,5 \\
\hline Итого & & & \\
\hline & & & \\
\hline
\end{tabular}

формационного табло для срочного рынка, снижение размеров комиссионных сборов за услуги биржи. Диапазон конкурентных преимуществ УзРТСБ значительно расширен, что повышает привлекательность площадки за счет наличия широкой региональной сети, охватывающей всю республику, гарантированного исполнения биржевых сделок, новейших информационно-биржевых технологий, широкого набора торгуемых инструментов, высокого уровня сервиса информационных услуг, нормативно-методического обеспечения всей системы функционирования торговых механизмов.

При поддержке государственных структур экономического комплекса республики усовершенствован регламент осуществления биржевых сделок в различных сегментах биржевого товарного рынка, увеличены объем и ассортимент выставляемой на торги продукции. Современные торговые платформы позволяют брокерам участвовать в биржевых торгах с любого рабочего места посредством подключения к ним большого количества участников.

Структурным преобразованиям экономики, повышению деловой активности и финансовой устойчивости хозяйствующих субъектов способствовала проводимая рациональная налоговая политика, направленная, в первую очередь, на сокращение налогового бремени. Так, в
2011 г. совокупное налоговое бремя по сравнению с 1991 г. снизилось почти в 2 раза - с 41,2 до $22 \%$ к ВВП (рис.).

Росту инвестиционной деятельности хозяйствующих субъектов способствовало снижение в 2011 г. с 7 до 6\% ставки единого налогового платежа для микрофирм и малых предприятий, что позволило направить около 80,3 млрд сум высвободившихся средств, в первую очередь, на технологическое обновление производства и внедрение новой современной техники. В истекшем году большое внимание уделялось проведению активной инвестиционной политики, направленной на ускорение модернизации, технического и технологического перевооружения действующих и создание новых современных высокотехнологичных производств.

В 2011 г. были освоены капитальные вложения за счет всех источников финансирования на сумму свыше 10,8 млрд долл. США. Доля инвестиций в ВВП составила $23,9 \%$, что свидетельствует о высокой активности инвестиционного процесса в стране. В реальный сектор экономики привлечено иностранных инвестиций в объеме почти 2,9 млрд долл. США, из которых 78,8\% составляют прямые иностранные инвестиции.

Кардинально меняется качественная структура кредитного портфеля банков. Если в 2000 г. структура кредитного портфеля на 54\% была 


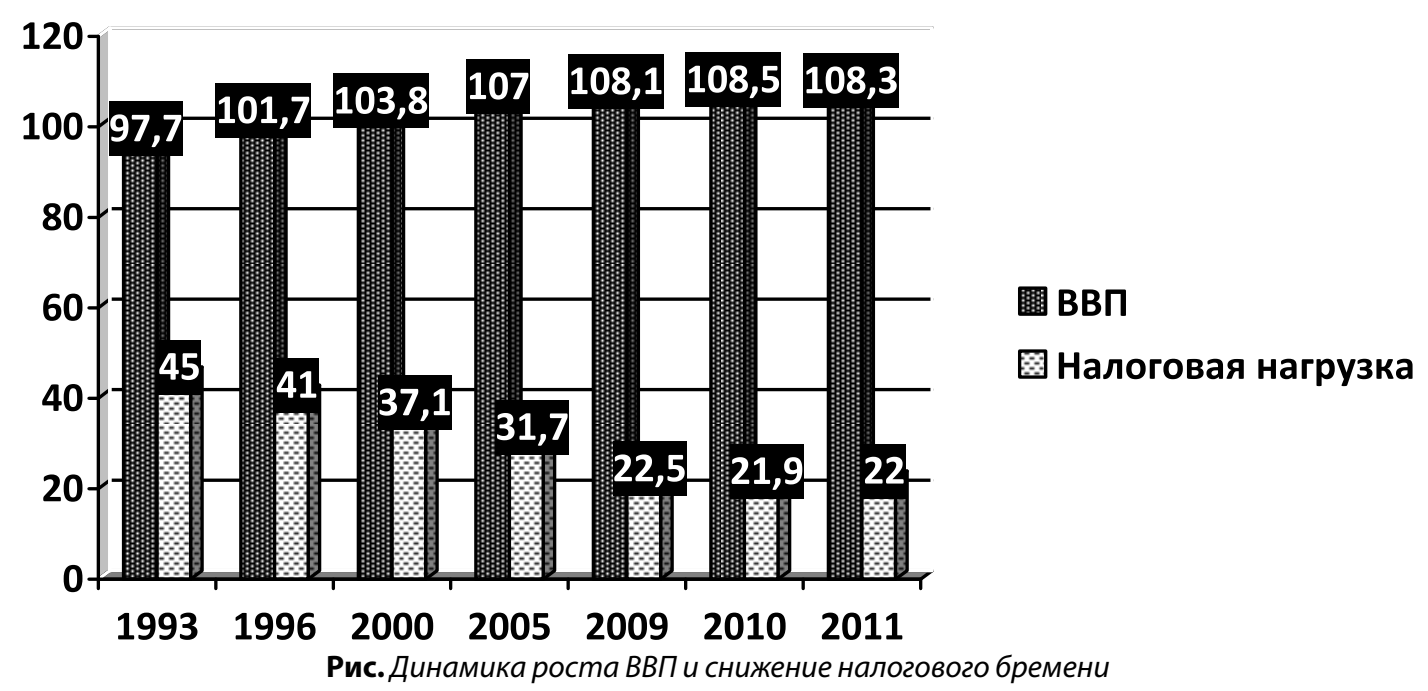

сформирована за счет внешних заимствований, то в 2011 г. 85,3\% кредитного портфеля сформировано за счет внутренних источников - депозитов юридических и физических лиц. Растет инвестиционная активность коммерческих банков. При этом свыше $75 \%$ вложений коммерческих банков - это долгосрочные инвестиционные кредиты сроком свыше трех лет. В целом за последние десять лет кредитование реального сектора экономики нашими банками возросло в 7 раз.

В 2011 г. были предприняты дополнительные меры по увеличению кредитования субъектов малого бизнеса и частного предпринимательства. С этой целью доходы коммерческих банков, получаемые от предоставления кредитов за счет ресурсов специального Фонда льготного кредитования, освобождены от уплаты налога на прибыль юридических лиц при условии целевого направления высвобождаемых средств на увеличение ресурсной базы указанного фонда до 1 января 2016 г. Коммерческим банкам при выдаче кредитов субъектам малого предпринимательства предоставлено право учитывать в общей сумме кредита расходы, связанные с оформлением залогового обеспечения заемщика. Кроме того, в республике создан Фонд финансирования подготовки проектной документации по инвестиционным проектам при Ассоциации банков Узбекистана, основными задачами которого определены конкурсный отбор проектных идей и финансирование разработки их проектной документации в приоритетных направлениях развития экономики, а также содействие в организации финансирования инвестиционных проектов кредитными организациями республики.

Для формирования максимально благоприятной деловой среды для дальнейшего развития малого бизнеса и частного предпринимательства счета субъектов малого бизнеса в национальной валюте открываются без взимания платы, а их кредитные заявки рассматриваются коммерческими банками в течение трех банковских дней.

В Узбекистане последовательно и целенаправленно реализуются меры по дальнейшей капитализации банков, повышению их устойчивости и ликвидности. На протяжении последних пяти лет показатель достаточности капитала банковского сектора находится на уровне в три раза превышающем международный норматив в размере $8 \%$, установленный Базельским комитетом по банковскому надзору.

Следует с удовлетворением отметить, что такие авторитетные международные рейтинговые агентства, как «Стандарт энд Пурс», «Мудис» и «Фитч Рейтингс» второй год подряд присваивают банковской системе Узбекистана рейтинговую оценку на уровне «стабильный», причем количество коммерческих банков республики, имеющих такую оценку, растет из года в год. Если в 2010 г. 15 коммерческих банков страны получили рейтинг «стабильный», то сегодня их количество достигло 23, их активы составляют более $98 \%$ от совокупных активов всей банковской системы республики.

Особого внимания заслуживает тот факт, что в Узбекистане в условиях всемирного финансовоэкономического кризиса политика государства была направлена, прежде всего, на недопущение снижения уровня жизни населения. Важным моментом, отличающим Антикризисную программу Узбекистана от программ других стран СНГ, явилось то, что она учитывала социальные факторы. Анализ антикризисных программ правительств ряда стран СНГ показал, что основ- 
ной акцент был сделан на стабилизацию финансового сектора, развитие инфраструктуры, малого и среднего бизнеса. При этом социальная составляющая поддержания уровня жизни населения в кризисный период была выведена за рамки антикризисных программ. Создание рабочих мест в результате развития малого бизнеса и индивидуального предпринимательства, обеспечения надомного труда на базе кооперации с промышленными предприятиями, а также ввода новых объектов, реконструкции и расширения действующих производств, встало мощным заслоном на пути обвального роста безработицы и усилению пессимизма в социальных настроениях общества, наблюдавшегося в других странах СНГ. Четкая социальная направленность программных мер также выражена во всесторонней государственной поддержке науки, образования, здравоохранения и культуры. Особое внимание уделяется вопросам реализации мер по увеличению внутреннего спроса за счет мобилизации и дальнейшего стимулирования участия банковских структур, хозяйствующих субъектов и населения в инвестиционных процессах. Примером реализации подобных проектов может стать Программа по ускоренному развитию и строительству жилья и социальной инфраструктуры на селе, призванной коренным образом переустроить и обновить облик села на современной архитектурной и индустриальной основе, повысить уровень жизни населения на селе и приблизить ее к городским условиям. Для реализации этой крупнейшей программы, рассчитанной на длительную перспективу, создан мощный проектный, индустриально-строительный, инженерно-технический потенциал и необходимые организационные структуры, стимулирующие меры и преференции.

Вместе с тем влияние кризиса на экономику Узбекистана будет осуществляться по следующим направлениям:

- движение капитала;

- сокращение экспортных доходов;

- напряженности на рынке труда.

Показатели основных индикаторов - валютные курсы, цены на сырье - часто снижаются или увеличиваются на десятки процентов. Так, золото весной 2011 г. достигло отметки 1500 долл. США за унцию, а в августе 2011 г. уже приблизилось к уровню 2000 долл. Однако уже в сентябре 2011 г. цены на золото упали до уровня 1750 долл. за унцию. В марте 2012 г. золото на мировых биржах пока держится выше 1660 долл. за унцию. Разнонаправленная динамика цен на золото оказывает влияние на курсы таких ведущих мировых валют, как доллар, евро, швейцарский франк, фунт стерлингов, иена, а также на цены экспорта и импорта. Дальнейшее ослабление устойчивости ориентиров в международной финансовой системе чревато потерей ориентации мировой экономики, резким изменением потоков капиталов, что может негативно сказаться на экономике Узбекистана.

В базовых вариантах роста мировой экономики потребление природного газа увеличивается в среднем на 1,8\% ежегодно до 2014 г. Эти темпы роста, по данным U.S. Energy Information Administration, сохранятся до 2020 г. Насыщение глобального рынка сбыта газа, возникшее в результате резкого роста добычи нетрадиционного газа в США и увеличения объемов производства сжиженного природного газа может оказывать давление на экспортеров газа, вынуждая их отказаться от привязки к ценам на нефть. В этом сценарии рост конкурентоспособного предложения природного газа по сравнению с другими видами ископаемого топлива позволит увеличить спрос на газ, особенно в европейском секторе электроэнергетики. В дальнейшем растущая потребность в импорте, в первую очередь в Европе и в перспективе в Китае, скорее всего, восстановит баланс, обусловит опережающий рост спроса и увеличит загрузку мощностей добычи и транспортной инфраструктуры. Наиболее быстрыми темпами спрос на природный газ будет увеличиваться в Китае - в среднем почти на $6 \%$ в год. Спрос Китая будет и самым объемным, на Китай приходится более одной пятой части увеличения глобального спроса.

Ситуация на мировом рынке меди, по оценкам Международной медной группы (International Copper Study Group, ICSG), в 2011 г. еще несколько улучшилась по сравнению с благоприятным 2010 г. и характеризуется постепенным уменьшением превышения предложения над спросом (с учетом сезонной очистки). В то же время рост реального мирового производства и потребления меди в 2011 г. был достаточно вялым. Производители не стремились наращивать выпуск на фоне ожидаемого замедления темпов роста мировой экономики и снижения текущего потребления меди Китаем на $7 \%$, в том числе падения нетто-импорта на 40\%. В течение прогнозного периода до 2014 г. ожидается эскала- 
ция долгового кризиса ведущих стран, чьи валюты являются резервными, прежде всего США и зоны евро. Динамика этого процесса будет основным фактором, определяющим цены на медь. Поэтому в 2012-2014 гг. вероятно появление устойчивого дефицита предложения меди. В результате мировая цена меди к 2014 г. может находиться в диапазоне от 9 тыс. до 10 тыс. долл/т.

В случае нового кризиса рынки и деловая активность будут замирать, спрос на сырье снизится, стоимость кредита подскочит, а возможности его привлекать вновь будут крайне ограниченными. Капитал вернется на развитые рынки, где вырастут ставки. Структура инвестиционного портфеля будет следующая: долговые инструменты (бумаги развивающихся рынков и высокодоходные облигации) - 43\%, акции - 41\%, золото - 7\%, нефть - 6\%, остальную часть составят наличные $(<3 \%)$. Мы имеем быстрый рост притока капитала, и никто не гарантирует, что в условиях ухудшающейся мировой конъюнктуры мы сможем продолжать занимать в тех же объемах (с учетом реализации проектов по модернизации).

Стратегия роста конкурентоспособности республики строится на региональных и отраслевых особенностях, которые превращаются в источники конкурентных преимуществ. В условиях Узбекистана с учетом территориальноотраслевых особенностей необходимо оценить конкурентный потенциал следующих секторов национальной экономики:

— с учетом особенностей природно-климатических условий агропромышленный комплекс может поставлять уникальную по свойствам сельскохозяйственную продукцию на внешние рынки, развитую систему инфраструктуры, исследовательскую базу, подготовку кадров, исторический опыт земледелия и другие компоненты кластерной структуры;

- перспективной институциональной формой повышения конкурентоспособности и инвестиционной привлекательности химической отрасли является перевод ее на кластерный тип развития. Имеется потенциал сырьевой базы для развития производства минеральных удобрений и газо-химического комплекса с географически близкими рынками сбыта, производственные мощности и предприятия-лидеры и др.;

- с точки зрения роста конкурентоспособности национальной экономики важное значение будет иметь развитие сектора информа- ционно-коммуникационных технологий (рост парков компьютерной техники, развитие телекоммуникационной инфраструктуры, снижение стоимости ее услуг, решение социально-экономических задач информатизации, рост спроса на услуги в сектор электронной коммерции, рост экспорта услуг в области аутсорсинга и разработки программного обеспечения);

- устойчивое развитие экономики отдельных регионов республики, равно как и их конкурентные позиции в национальном и глобальном уровне предопределяются состоянием и эффективностью использования уникального историко-культурного и природно-ресурсного потенциала. Формирование межотраслевых туристических - рекреационных зон, на базе гг. Самарканда, Бухары и Хивы предполагает реализацию национальной программы развития туризма и инициатив местных органов власти, направленных на реализацию стратегии повышения конкурентоспособности экономики региона (при государственной поддержке развития инфраструктуры, нормативно-правовой базы и др.).

Вместе с тем успех в реализации стратегии роста конкурентоспособности зависит от правильной комбинации главных составляющих внутренней экономической политики, которые взаимно дополняют и усиливают друг друга:

- поддержание устойчивого макроэкономического роста и управляемой инфляции путем проведения эффективной фискальной и монетарной политики;

- формирование стратегии экспортоориентированной индустриализации, которая подразумевает эффективную модернизацию и углубление структурных реформ, обеспечивающих рост эффективности использования и распределения ресурсов в экономике;

- обеспечение высокого качества государственного регулирования экономики;

- эффективное функционирование естественных монополий, производственной и социальной инфраструктуры;

- внедрение международных стандартов бухгалтерского учета и отчетности;

- обеспечение системы законодательного регулирования экономики, которая гарантировала бы защиту прав частной собственности и исполнение контрактов;

- обеспечение социального консенсуса и развития институтов гражданского общества, со- 
трудничество и партнерство между основными экономическими группами и слоями населения.

Современный долговой кризис, другие экономические и политические проблемы, возникшие в западных странах, могут иметь определенные последствия для рынка труда Узбекистана. По нашим оценкам, они могут отразиться на процессах внешней трудовой миграции населения, привести к напряженности на локальных рынках труда и росту безработицы.

В настоящее время в Узбекистане трудовая миграция населения является самым мощным и растущим миграционным потоком. По некоторым оценкам, численность трудовых мигрантов Узбекистана, работающих за рубежом, составляет от 3 до 5 млн чел. ${ }^{1}$ По нашему мнению, эта численность является нереальной, чрезмерно преувеличенной. Исследования показывают, что основная масса наших трудовых мигрантов (не менее 70\%) работает в России. По данным ФМС России, современная численность граждан Узбекистана, официально получивших разрешение на работу в Российской Федерации, колеблется в пределах 550-650 тыс. человек, а с лицами, имеющими нелегальный статус, она может составить 750-800 тыс. человек. С учетом других стран общая численность трудовых мигрантов из Узбекистана можно оценить в 1,0-1,1 млн чел.

На миграционные процессы большое воздействие оказывает конъюнктура на мировых рынках, особенно в кризисные периоды. В частности, мировой финансовый кризис оказал немалое воздействие на масштабы трудовой миграции из Узбекистана в Россию. Об этом свидетельствуют, во-первых, возврат некоторой чести трудовых мигрантов в 2008 г., в обычный сезон наиболее активной работы, во-вторых, снижение объемов денежных переводов (по данным Центробанка РФ, за первый квартал 2009 г. на $37 \%$ ).

Прежде всего, из-за сокращения потребности в рабочей силы в принимающих странах можно ожидать снижения масштабов трудовой миграции. Для Узбекистана это можно считать позитивным последствием, т. к. наряду с немалыми экономическими эффектами, миграционные процессы имеют негативные стороны.

\footnotetext{
1 Влияние экономического кризиса на миграционные тенденции и миграционную политику в Российской Федерации и регионе Восточной Европы и Центральной Азии. Издание МОМ. Москва, 2009, с. 38.
}

Происходят немалые потери трудового потенциала республики и ухудшается качественный состав трудовых ресурсов. В странах приема трудовые мигранты используются в основном не по своим профессиям и специальностям, утрачивают свои профессиональные знания и квалификацию, зачастую безвозвратно. С рынка труда Узбекистана уходят наиболее мобильные, дееспособные, работящие люди, ослабляя национальный рынок труда. Не менее сильны негативные социально-демографические последствия: ухудшение здоровья мигрантов, осложнение семейных отношений, а иногда и распад семей, снижение внимания к воспитанию детей, что в дальнейшем может привести к ухудшению демографической ситуации и качества населения.

Одновременно со снижением общих объемов трудовой миграции могут относительно увеличиваться размеры нелегальной занятости наших мигрантов. В службах занятости России и западных стран сокращается заявленная предприятиями потребность в работниках, этим пользуются работодатели, заинтересованные в незаконном привлечении мигрантов и экономии на заработной плате. Рост численности трудовых мигрантов с неопределенным статусом чрезвычайно ухудшает их правовое и социальное положение на российском рынке труда.

Таким образом, негативные последствия кризисных ситуаций глобального плана могут выразиться и в сокращении объемов денежных переводов (это уже имело место в 2008-2009 гг.), что снижает экономические эффекты трудовой миграции.

Исходя из всего вышесказанного можно сделать вывод, что в нынешней ситуации единственный путь для ускоренного развития национальной экономики - это расширение взаимодействия с мировыми рынками при активной политике по защите и продвижению интересов национальных производителей. В этих условиях развитие конкурентоспособной экономики приобретает первостепенное значение, поскольку обостряется борьба предприятий за финансовые ресурсы, за удовлетворение снижающегося спроса на товары и услуги. 


\section{Информация об авторах}

Расулев Алишер Файзиевич (Ташкент) - доктор экономических наук, профессор, директор, Институт экономики Академии наук Республики Узбекистан (100060, г. Ташкент, пр. Шахрисабзкий, 5, e-mail: arasulev@yandex.ru).

Тростянский Дмитрий Валерьевич (Ташкент) - доктор экономических наук, заведующий отделом, Институт экономики Академии наук Республики Узбекистан (100060, г. Ташкент, пр. Шахрисабзкий, 5, e-mail: tro7@yandex.ru).

\section{A. F. Rasulev, D. V. Trostyanskiy}

\section{Modernaspects ofensuring economic securityin Uzbekistan}

This paper reveals the dynamics of the main indicators of Uzbekistan'seconomic security at the present stage of development. Particular attention is paid to macro-and mesoeconomic aspects of sustainable development of national economy, implementation of institutional reforms to ensure competition, as well as favorable investment and business climate. The authors reveal potential risks and threats to the national economy in the movement of capital, reduction of export earnings, a tightening labor market, as well as suggest guidelines for improving the competitiveness atterritorial and sectoral levels.

Keywords: economic security, potential risks and threats, threshold values, strategy of competitiveness

\section{Information about the authors}

Rasulev Alisher Fayzievich (Tashkent, Respublic of Uzbekistan) - Doctor of Economics,Professor, Director of the Institute of Economics of the Academy of Sciences of the Republic of Uzbekistan, (100060, Tashkent, pr. Shahrisabzky, 5. e-mail: arasulev@ yandex.ru).

Trostyanskiy Dmitriy Valer'evich (Tashkent, Respublic of Uzbekistan) - Doctor of Economics, Head of the Institute of Economics of the Academy of Sciences of the Republic of Uzbekistan (100060, Tashkent, pr. Shahrisabzky, 5. E-mail: tro7@yandex. $\mathrm{ru})$. 